\title{
Partitives: An Exploration in Cognitive Grammar
}

\author{
Zeki Hamawand ${ }^{1}$ \\ ${ }^{1}$ Department of English, College of Education, University of Kirkuk, Kirkuk, Iraq \\ Correspondence: Zeki Hamawand, Department of English, College of Education, University of Kirkuk, Kirkuk, \\ Iraq. E-mail: zeki.hamawand@gmail.com
}

Received: October 6, 2013 Accepted: January 20, 2014 Online Published: January 24, 2014

doi:10.5539/ijel.v4n1p112 URL: http://dx.doi.org/10.5539/ijel.v4n1p112

\begin{abstract}
This paper provides a new analysis of partitives in English, words that denote parts of nouns as in a pinch of salt, a dash of vinegar, a pat of butter, a stick of chalk, and so on. It seeks to substantiate two fundamental tenets of Cognitive Grammar with respect to such words. One tenet is that the meaning of a linguistic expression is best understood in terms of the domain to which it belongs. On the basis of this tenet, the paper argues that partitives form sets in which they highlight similarities in general but differences in specifics. A partitive has not only a syntactic function but also semantic content which conditions its presence in a phrase. The other tenet is that the use of a linguistic expression is governed by the particular construal imposed on its content. On the basis of this tenet, the paper argues that the use of a partitive stems from the particular construal the speaker chooses to describe a situation. The occurrence of two or more partitives before a noun brings about semantic contrast, in which each partitive represents a different construal.
\end{abstract}

Keywords: conceptual content, construal, domain, partitive, perspective

\section{Introduction}

In English grammar, nouns can be classified into count and non-count. A count noun has both a singular and a plural form, as in book/books. Reference to a general count noun is made by the use of an indefinite article as in a book. Reference to a specific count noun is made by the use of a definite article as in the book, or a deictic expression as in this book. A count noun has bounded structure in that it designates an entity with inherent edges, which can thus be divided and calculated. An amount of a count noun is conceived as a set of individuals. A noncount noun, by contrast, does not have a plural form, as in sugar/*sugars. A non-count noun does not have inherent edges and therefore cannot be divided and calculated. A non-count noun is conceived as an undifferentiated mass. It does not consist of separate parts. In order to refer to a part of a non-count noun or refer to a specific quantity of it, English grammar provides its speakers with certain means called partitives.

A partitive construction is defined by Huddleston and Pullum (2005, p. 98) as a noun phrase consisting of a partitive, specifying a part, followed by the preposition of and a noun, denoting the whole. For example, the noun phrase a clod of mud is a partitive construction in which clod is a partitive followed by the preposition of and together precede the noun $m u d$, with clod referring to only a part of $m u d$. A clod of mud is a small mass of mud. A partitive is then a word that individuates a part of a noun as distinct from a whole. Reference to a part of a non-count noun is achieved by individuation, defined by Lyons (1977) as the process of extracting a distinct entity from a continuum of reference. It is the process of referring to entities as discrete individual units.

As a means of expressing individuation, partitives, as Alexander (1988, p. 53) states, serve to refer to specific pieces of non-count substances, or to a limited number of count objects. In Langacker (1991a), partitives act as relative quantifiers of their complement nouns because they specify a quantity in relation to the entity of reference. The semantics of a partitive construction is dependent not only on the semantics of the partitive denoting the part but also on the noun denoting the whole. Therefore, both the partitive and the following $o f$-phrase contribute equally to the creation of the partitive construction. Prototypically, partitives are used before non-count concrete nouns, as in a slice of bread. Peripherally, they can be used before non-count abstract nouns, as in a piece of advice and before count concrete nouns, as in a packet of cigarettes.

An examination of some data shows that partitives occur in a variety of constructions in which they manifest various linguistic phenomena, as illustrated by the following examples: 
(1) A flash/*gust of lightning lit up the sky.

A gust $/ *$ flash of wind blew the door shut.

A clap/*bang of thunder broke the silence.

(2) a piece of cake/chalk/coal/land/paper

a piece of advice/information/news/research/work

a bit of cheese/chocolate/cloth/rice/wood

a bit of concern/fun/information/knowledge/support

(3) a pint of $=$ a unit of measuring liquid

a quart of $=$ a unit of measuring liquid

a gallon of $=$ a unit of measuring liquid

(4) a loaf of bread

a slice of bread

a crumb of bread

The examples in (1) and (2) demonstrate the phenomenon of collocability, the tendency of lexical items to collocate.

The lexical items in (1) tend to have a narrow range of collocation. The partitive a flash of occurs only with lightning, a gust of occurs only with wind, and a clap of occurs only with thunder. The partitive a flash of means a sudden bright light that quickly disappears. The partitive a gust of means a sudden strong movement of wind. The partitive a clap of means a sudden loud noise. Such lexical items are said to exhibit specific collocational restrictions. The restriction pertains to the semantics of the partitive and the following noun.

The lexical items in (2) tend to have a broad range of collocation. The partitive a piece of, for example, tends to collocate with both concrete words such as cake, chalk, coal, land and paper, and abstract words such as advice, information, news, research and work. A piece of implies a small quantity, i.e., a part of something that has been separated from the rest. Such lexical items are said to exhibit collocational flexibility. The flexibility pertains to the semantic compatibility between the partitive and the following noun.

The examples in (3) demonstrate the phenomenon of lexical relationship, the tendency of two or more partitives to denote the same concept. The partitives a pint of, a quart of and a gallon of represent the concept of measure. They are basic units for measuring liquid. Concerning this phenomenon, two questions are posed: The first is: Do partitives form semantic sets when they share the same concept, and if so, on what basis are they grouped together? The second is: Do they perform specific functions within the sets, and if so, how do they differ from one another?

The examples in (4) demonstrate the phenomenon of lexical alternation, the tendency of two or more partitives to occur before the same noun. The partitives a loaf of, a slice of and a crumb of are followed by the noun bread. Concerning this phenomenon, two questions are posed. The first is: Do partitives signal different meanings when they occur before a noun, and if so, in what respect are they different? The second is: Do they impose distinct readings on the construction, and if so, in what way are they distinct?

To answer the questions above, a new approach is needed. The new approach has to address these two linguistic phenomena, lexical relationship, whereby partitives cluster in sets defined by two types of relation: one is of similarity vis-à-vis the overall concept of the set they form; the other is of difference with respect to the specific functions they perform within the set, and lexical alternation, whereby two or more partitives alternate before the same noun. In addition to phonological distinctness, the alternatives exhibit semantic dissimilarity. Each alternative has a distinct function to carry out in the language. The new approach adopted is Cognitive Grammar. It is chosen because it is adept at handling intricacies of linguistic data. It provides linguists with the necessary tools to convincingly account for the semantics of grammatical and lexical structures. The viability of the new approach rests on crucial tenets, which gives meaning a central position in language enquiry.

The present research then aims to provide new insights into the meanings of partitives in English. It uses a descriptive analysis to answer the questions. The sources of the data include major dictionaries of English language such as Longman Language Activator (2002), Cambridge Advanced Learner's Dictionary (2003), The New Merriam-Webster Dictionary (1989), Oxford Advanced Learner's Dictionary of Current English (2005), Longman Dictionary of Contemporary English (2009), and modern reference grammars of English such as Quirk 
et al. (1985), Biber et al. (1999), Huddleston and Pullum (2002) and Alexander (1988). The paper is organized as follows. In section 2, I briefly review the literature. In section 3, I introduce the new approach and elaborate on its central tenets. In section 4, I probe the phenomenon of lexical relationship, namely the exact meaning of a lexical item is identified relative to the domain in which it is embedded. In section 5, I investigate the phenomenon of lexical alternation, namely the use of a lexical item is the result of the particular construal imposed on a situation. In section 6 , I present the findings.

\section{Review of the Literature}

The area of partitives in English has long been of concern to linguists interested in the semantics of the language. The literature, however, is rather scarce and provides no in-depth or exhaustive treatment of partitives. One reason for this is that linguists refrain from talking about such an area because it is fraught with complications. Another, more important, reason is that linguists lack the necessary tools to investigate such a significant topic in semantics. To get a clear picture of the treatment so far, I classify the literature into three categories: language dictionaries, reference grammars and linguistic monographs. The purpose of the review is not to criticise any of these treatments, but to see if they can benefit the current analysis or to see if the present analysis can build on them. Despite their limitations, the treatments provide some clues as to how the topic is addressed.

My first review of the literature covers language dictionaries. Perusing some major English dictionaries of language like Cambridge Advanced Learner's Dictionary (2003), The New Merriam-Webster Dictionary (1989) and Oxford Advanced Learner's Dictionary of Current English (2005) for answers to the aforementioned questions shows that they display considerable deficiencies. First, the dictionaries give only a very sketchy account of partitives, failing thus to provide accurate definitions of them. Second, the dictionaries allot the partitives separate entries, failing thus to make a comparison between them. Third, the dictionaries present pairs of partitives preceding the same nouns as semantically interchangeable, failing thus to offer explanations for the choice between them. In sum, dictionaries do not provide language users with all the necessary information regarding partitives. The only exception is the Longman Language Activator (2002), where some of the partitives are grouped together, but still they are not clearly distinguished.

My second review of the literature covers reference grammars. Scanning grammars of language like Quirk et al. (1985), Biber et al. (1999) and Huddleston and Pullum (2002) for answers to the aforementioned questions shows that they have some shortcomings. One shortcoming is that these grammars present only a superficial account of partitives. A detailed description of the exact behaviour of any partitive is lacking. Another shortcoming is that these grammars make no reference to alternative partitives. An accurate portrayal of the alternative partitives is missing. A further shortcoming is that these grammars rarely differentiate between the emerging pairs. A full account of the distinction in meaning between such pairs is absent. In brief, such a state of affairs surely blurs the distinctions between the partitives.

My third and final review of the literature includes linguistic monographs. Scrutinising works like Jackendoff (1991), Hoeksema (ed.) (1996) and Koptjevskaja-Tamm (2006) in search of answers to the aforementioned questions shows that they suffer some inadequacies. One inadequacy is that these works miss drawing a fully-articulated account for each partitive. Another inadequacy is that these works fail to reveal the distinctive roles which the partitives play in the language. A further inadequacy is that these works do not capture the differences in meaning between alternative partitives in a systematic way. In short, these works overlook the fact that alternation is a widespread phenomenon in language.

\section{The New Approach}

The new approach adopted in the present paper is Cognitive Grammar as described in Langacker (1987, 1991a, 1991b, 1999, 2008). Cognitive Grammar attempts to describe the cognitive principles that motivate the formation and use of linguistic units of varying degrees of complexity. Cognitive Grammar rests on a number of fundamental tenets. First, language is symbolic in nature. It resides in associations of phonological and semantic structures. It tries, therefore, to clarify the interaction between form and meaning in the make-up of linguistic expressions. Second, grammatical structure does not assume any underlying structure. Rather, it is entirely overt and represents a means for carrying semantic content. It attempts, therefore, to describe the cognitive principles that motivate the formation and use of linguistic expressions of varying degrees of complexity. Third, grammar is usage-based. Knowledge of language is based on actual usage. It is dynamic and evolves in accordance with speakers' experiences. It tries, therefore, to explain language structure by generalising over specific linguistic forms taken from empirical data.

Cognitive Grammar is built on crucial theories of meaning, two of which are relevant to the analysis of partitives. The first is that lexical items gather together in cognitive domains. Langacker (1987, pp. I, 147) writes: "All linguistic units are context-dependent to some degree. A context for the characterization of a semantic unit is referred to as a domain. Domains are necessarily cognitive entities: mental experiences, representational spaces, 
concepts, or conceptual complexes". According to Hamawand (2011, p. 46), a domain is a knowledge background in terms of which the meanings of lexical items can be properly described. The knowledge is based on experiences derived from beliefs, customs and practices. The second is that lexical items embody alternative dimensions of construal. Langacker (1997, pp. 4-5) writes: "A semantic structure includes both conceptual content and a particular way of construing that content". The meaning of a construction is characterised in terms of two aspects: conceptual content and construal. Conceptual content refers to the semantic property inherent in a linguistic unit. According to Hamawand (2011, p. 49), construal refers to the act of describing the conceptual content in alternate ways, and choosing the appropriate linguistic structures to express them.

The following sections give details of the two theories of meaning which apply to partitives.

\section{The Domain Theory}

Cognitive Grammar characterises lexical relationships in terms of the domain theory, as exemplified by Langacker (1987, 1991a). In the light of this theory, concepts gather together in cognitive domains. A cognitive domain is a conceptual structure with respect to which concepts are described. In language, lexical items cluster in semantic sets. A linguistic domain is a knowledge structure relative to which the meanings of lexical items are identified. Within the domain, each item occupies a particular facet, which stands for a specific human experience. Therefore, to understand the meaning of any item, it is necessary first to understand the domain in which it is embedded and second to contrast it with its counterparts in the same domain. For example, the exact meaning of the word father cannot be identified without activating the domain of kinship as the background knowledge for its description.

The cognitive domain theory is applicable to all areas of language (Note 1). In the present analysis, I employ it in the description of partitives. In this regard, I argue that partitives form different domains in the sense that to understand the meaning of any partitive it is necessary to understand the properties of the domain in which it occurs as well as the properties of the other members of the domain. That is, the meaning of a partitive depends on the domain to which it belongs, knowledge of which is necessary for its appropriate use. The meaning of a partitive arises from its relations of similarity and contrast with other partitives in the domain. A domain is used as a cognitive operation which allows one to describe the specification of partitives and provide the motivation for their use in language.

To make this clear, let us take an example. The partitives drop, blob and pool form the domain of amount. This has to do with a mass especially of liquid which cannot be counted. Within this domain, each partitive occupies a particular facet and expresses a particular meaning. A drop is a very small amount of thin liquid. This is shown in examples such as $A$ few drops of rain/sweat/blood ran down her forehead. A blob is a small amount of thick liquid. This is shown in examples such as She dropped a blob of paint/glue/grease on the carpet. A pool is an area of liquid lying on a surface. This is shown in examples such as A guard found him lying in a pool of blood/oil/water. Although the partitives collocate with types of liquid, they differ in the nature of the liquid.

In what follows, I introduce the cognitive domains in which the partitives are placed. The goal is to show that the meaning of a partitive is best identified first by linking it to the cognitive context in which it is used, and second by contrasting it with the other parititives in the same domain. This helps to avoid the misconception of treating partitives in isolation, which is commonplace in pre-cognitive studies. The introduction comprises five steps. First, a list of the partitives is compiled by relying on the major dictionaries on English language. Second, the parititives are grouped together in cognitive domains relative to the concepts which they share. Third, the facets within each domain are identified, with each facet being allotted to a different partitive. Fourth, examples on the use of each partitive are given. Fifth, the exact meaning of each partitive is revealed.

\subsection{The Domain of CONTAINER}

The domain of CONTAINER is a conceptual area referring to a hollow object, made of wood, metal or plastic, which is used for holding soft or solid substance. A container appears in different sizes: large, medium and small. A large container is used to store a substantive amount of something. Linguistically, this facet is expressed by the partitives $a$ barrel of and $a$ tank of. A medium container is used to store a moderate amount of something. Linguistically, this facet is expressed by the partitives a bottle of, a bowl of, a jar of, a jug of and a pot of. A small container is used to store a little amount of something. Linguistically, this facet is expressed by the partitives a cup of, a glass of, a mug of, a tin of and a tube of. Although they are examples of container, they are not interchangeable. Each partitive is used for a particular purpose, and so accepts a particular type of substance.

The following examples show how each partitive behaves within the facet of large containers. 
(5) a. They bought $a$ barrel of beer for the party.

b. The long journey consumed a tank of petrol.

The sentences given in (5) contain partitives denoting containers of large size. Despite their similarity in size, they are assigned different functions in the language. In (5a), a barrel of is a large container, made of wood or metal, used for storing beer or wine. In (5b), a tank of is a large container, made of metal, used for storing fuel or water.

The following examples show how each partitive activates a different facet within the facet of medium-sized containers.

(6) a. Shall we have a bottle of wine?

b. Would you like a bowl of rice?

c. The shopper wants a jar of jam.

d. She asked for a jug of water.

e. A pot of soup is on the stove.

The sentences given in (6) contain partitives denoting containers of medium size. In spite of their similarity in size, they are ascribed to different contexts. In (6a), a bottle of is a medium container with a narrow top, made of glass or plastic, used mainly for holding drinks: milk, lemonade or wine. In (6b), a bowl of is a medium round container that is open at the top, made of china, glass or wood, used mainly for holding food: fruit, soup or sugar. In (6c), a jar of is a medium container with a lid, made of glass or pottery, used mainly for holding jam, honey or olives. In (6d), a jug of is a medium container, made of pottery, used mainly for holding liquids: milk, cream or water. In (6e), a pot of is a medium round container, made of metal or pottery, used mainly for cooking food and holding plants or hot drinks.

The following examples show how each partitive behaves within the facet of small containers.

(7) a. She always has a cup of tea at bedtime.

b. Would you like a glass of wine?

c. I made myself a mug of cocoa.

d. She bought $a$ tin of beans.

e. She bought $a$ tube of toothpaste.

The sentences given in (7) contain partitives denoting containers of small size. Notwithstanding their similarity in size, they are used in different situations. In (7a), a cup of is a small round container with a handle, made of porcelain, used mainly for holding hot drinks. In (7b), a glass of is a small container, made of glass, used mainly for holding soft and hard drinks: milk, lemonade or wine. In (7c), a mug of is a tall cup with straight sides, made of pottery, used mainly for holding hot drinks: tea, coffee or cocoa. In (7d), a tin of is a small container with a lid, made of tinplate steel or aluminium, used mainly for storing food: peas, beans or fruit. In (7e), a tube of is a long thin container, made of plastic or soft metal, used mainly for storing thick liquids: toothpaste, paint or ointment.

\subsection{The Domain of QUANTITY}

The domain of QUANTITY is a conceptual field referring to an amount of something that cannot be counted, or a collection of things that can be counted. Quantity has two facets: amount and collection. Amount refers to a quantity of something which cannot be counted. It takes different shapes. The first is a thick flat piece. Linguistically, candidates for this facet are a bar of, a block of, a cube of, a plank of and a slab of. The second is a thin flat piece. Linguistically, candidates for this facet are a pane of, a sheet of, a slice of and a slip of. The third is a mark, spot or fragment. Linguistically, candidates for this facet are a crumb of, a flake of, a fleck of, a grain of, a morsel of, a speck of, a drop of and a fragment of. The partitives are not alike in behaviour. They differ with reference to shape and the thing they precede.

Collection refers to a group of similar objects which are kept together and can be counted. The first group denotes stack. Linguistically, representatives of this facet are a heap of, a mound of, a pile of, a stack of and $a$ pack of. The second group denotes connection. Linguistically, representatives of this facet are a bunch of, a bundle of, a sheaf of, a wad of and a bouquet of. The third group denotes arrangement. Linguistically, representatives of this facet are a clump of, a fleet of, a set of and a string of. The fourth group denotes people. Linguistically, representatives of this facet are a horde of, a throng of, a crush of, a gang of and a panel of. The 
fifth group denotes animals. Linguistically, representatives of this facet are a shoal of, a flock of, a herd of, a pack of, a litter of and a swarm of. The partitives are distinguishable in behaviour. The key factor distinguishing between them pertains to the nature of the following nouns.

The following examples illustrate how each partitive signifies a different feature within the facet of amount.

(8) a. I am used to eating a bar of chocolate every day.

b. The fish was lying on a block of ice.

c. She dropped a cube of sugar into her tea.

d. We used a plank of wood to cross the ditch.

e. They used slabs of concrete to build the pathway.

The sentences cited in (8) contain partitives designating thick flat pieces. Still, there is a difference between them in usage. In (8a), a bar of is a thick flat piece of something such as metal, soap or chocolate. In (8b), a block of is a thick flat piece of something with straight sides such as concrete, wood or ice. In (8c), a cube of is a thick flat piece of something with six equal square sides such as sugar or ice. In (8d), a plank of is a long thick flat piece of something such as wood. In (8e), a slab of is a thick flat heavy piece of something such as stone or concrete.

(9) a. The bullet shattered two panes of glass.

b. Write each answer on $a$ new sheet of paper.

c. There are three slices of plum cake on the plate.

d. She wrote her address down on a slip of paper.

The sentences cited in (9) contain partitives designating thin flat pieces. Nevertheless, there is a difference between them in language. In (9a), a pane of is a thin flat piece of glass which has been cut to the size of a window or door. In (9b), a sheet of is a thin flat piece of something such as paper, glass, or plastic, usually with four straight sides. In (9c), a slice of is a thin flat piece of food such as bread, meat or cake that has been cut from a bigger piece using a knife. In (9d), a slip of is a small, thin flat piece of paper, used for a particular purpose, a voting slip or a betting slip.

(10) a. There were $a$ few crumbs of bread on the plate.

b. Some flakes of paint fell from the ceiling.

c. There were flecks of mud on my trousers.

d. A few grains of salt were left in the salt pot.

e. Two birds were fighting over the last morsel of bread.

f. There is not a speck of dirt in their house.

g. There were drops of blood on the floor.

h. They found fragments of broken pottery on the floor.

The examples in (10) contain partitives designating marks, spots or fragments. Despite that, each partitive has its own sense in the language. In (10a), a crumb of is a dot of something dry such as bread, biscuit or cake. In (10b), a flake of is a blotch of something such as snow or paint. In (10c), a fleck of is a smudge of something such as dirt, dust, mud or paint. In (10d), a grain of is a particle of something hard such as sand or salt. In (10e), a morsel is a very small piece of food, used especially in literature. In (10f), a speck of is a stain of something such as dust or dirt. In (10g), a drop of is a splodge of something such as liquid. In (10h), a fragment of is a shard of something broken such as glass, bone or pottery.

The following examples illustrate how each partitive signifies a different feature within the facet of collection.

(11) a. There was a heap of blankets on the bed.

b. There is a mound of potatoes on the floor.

c. The manager had a pile of papers on his desk.

d. He chose The Economist from a stack of magazines.

e. After dinner, Frank got out a pack of cards.

The sentences cited in (11) contain partitives indicating a collection of things put one on top of the other. Each partitive, however, represents a particular facet, and so has a different use in the language. In (11a), a heap of is a 
collection of things lying one on top of the other in an untidy way, especially clothes or rubbish. In (11b), $a$ mound of is a collection of things, like a small hill, especially potatoes or stones. In (11c), a pile of is a collection of things positioned one on top of another, especially books, papers or dirty clothes. In (11d), a stack of is a collection of things put neatly on top of each other, especially magazines or dishes. In (11e), a pack of is a collection of things like playing cards.

(12) a. Has anyone seen a bunch of keys?

b. She gave a bundle of clothes to charity.

c. A lawyer walked in carrying a sheaf of papers.

d. She used a wad of tissues to wipe away the blood.

e. Chris sent me a bouquet of flowers when I was ill.

The sentences cited in (12) contain partitives indicating a collection of things that are tied together. Each partitive, nonetheless, represents a different facet, and so has a different role to play in the language. In (12a), $a$ bunch of is a collection of things held together like flowers, keys or grapes. In (12b), a bundle of is a collection of things fastened together like papers, clothes or sticks. In (12c), a sheaf of is a collection of things held together in a flat pile like paper or plant. In (12d), a wad of is a collection of things pressed tightly together like cash, banknotes or tissues. In (12e), a bouquet of is a collection of things that have been fastened together and attractively arranged so that they can be given as a present like flowers.

(13) a. There was a clump of roses in the garden.

b. The company owns a fleet of taxis in the city.

c. We bought them a set of cutlery as a present.

d. I gave her a string of pearls for her birthday.

The sentences cited in (13) contain partitives indicating a collection of things that grow very close together. Each partitive, nonetheless, represents a different facet, and so collocate with a different noun. In (13a), a clump of is a collection of things that grow together like trees, roses, grass or plants. In (13b), a fleet of is a collection of things operated or owned by a state or company like ships or vehicles. In (13c), a set of is a collection of similar things that belong together in some way like cutlery or tools. In (13d), a string of is a collection of several objects connected with a chain or thread like pearls, beads or lights.

(14) a. A horde of annoying students blocked the entrance.

b. A throng of excited fans gathered round the speaker.

c. I struggled through a crush of people to get to the door.

d. The police are working to track down a gang of thieves.

e. The competition will be judged by a panel of experts.

The sentences cited in (14) contain partitives indicating a group of people who do things together. Each partitive, nevertheless, epitomises a different facet, and so has a different application in the language. In (14a), a horde of is a large group of people behaving in a disapproving way, moving in a noisy uncontrolled way. In (14b), $a$ throng of is a large group of people in one place, especially admirers or supporters. In (14c), a crush of is a crowd of people who are forced to stand close together. In (14d), a gang of is a group of people, especially young men, who cause trouble and commit crime. In (14e), a panel of is a small group of people with specialist knowledge who have been chosen to give advice on a particular subject.

(15) a. There is a wonderful shoal of fish in the pond.

b. The farmer has a flock of around 100 sheep.

c. $A$ herd of cows was blocking the road.

d. A pack of dogs guarded the building.

e. The cat just had a litter of six kittens.

f. The dead sheep was covered with swarms of flies.

The sentences cited in (15) contain partitives indicating a group of animals. Each partitive, nonetheless, signals a different facet, and so has a different purpose in the language. In (15a), a shoal of is a large group of fish, dolphins or whales swimming together. The partitive a school of can be used in this sense. In (15b), a flock of is 
a group of sheep or birds. In (15c), a herd of is a group of cattle, cows, deer or elephants. The partitive $a$ drove of can be used in this sense. In (15d), a pack of is a group of dogs or wolves. In (15e), a litter of is a group of kittens or puppies born at one time to a particular mother. In (15f), a swarm of is a large group of insects all moving together like bees, wasps, ants or locusts. The partitives a plague of and a colony of can be used in this sense.

\subsection{The Domain of MEASURE}

The domain of MEASURE is a field of knowledge referring to units or things used for measuring the size or weight of something. The things measured are non-count nouns which require partitives to measure their quantities. Measure has two facets: precise and approximate. Precise means exact, no more and no less than a number or amount. Partitives symbolising the facet of precise measuring denote area, weight, volume and length. Units for measuring area are an acre of, a hectare of and a strip of. Units for measuring weight are $a$ kilo of, an ounce of, a pound of and a ton of. Units for measuring volume are a gallon of, a litre of, a pint of and a quart of. Units for measuring length are a metre of, a mile of and a yard of. Approximate means inexact: more or less than a number or amount. Partitives symbolising the facet of approximate measuring end in $-f u l$, which include $a$ cupful of, a fistful of, a handful of, a mouthful of and a spoonful of. Partitive expressions with -ful refer to containers or spaces which commonly hold different items.

The following examples indicate how each partitive plays a different role within the facet of precise measure.

(16) a. They own 200 acres of farmland in Scotland.

b. They plan to log 10 hectares of ancient forest.

c. There is a strip of sand between the cliffs and the sea.

d. They found a kilo of heroin secreted in his clothing.

e. The recipe calls for 10 ounces of plain flour.

f. The customer asked for a pound of minced beef.

g. They consume three tons of coal every year.

h. My car uses one gallon of fuel every 50 miles.

i. The tax increase will add $4 p$ to a litre of petrol.

$\mathrm{j}$. Add two pints of water to the mixture.

$\mathrm{k}$. I phoned down for some eggs, toast and a quart of milk.

1. They used a metre of wire for the table lamp.

$\mathrm{m}$. They need a mile of cable to connect the two stations.

$\mathrm{n}$. She needs 10 yards of cloth for the kitchen curtains.

The examples under (16) contain partitives signifying precise measure. Even so, each partitive symbolises a certain facet, and so has a different function in the language. The partitives in (16a-c) are units for measuring area. In (16a), an acre of is a unit for measuring area, equal to 4047 square metres or 4840 square yards. In (16b), a hectare of is a unit for measuring area, equal to 10.000 square metres. In (16c), a strip of is a long narrow area of land. The partitives in (16d-g) are units for measuring weight. In (16d), a kilo of is a unit for measuring weight, equal to 1000 grams. In (16e), an ounce of is a unit for measuring weight, equal to approximately 28 grams. In (16f), a pound of is a unit for measuring weight, equal to 454 grams. In (16g), a ton of is a unit for measuring weight, equal to 1000 kilogram. The partitives in (16h-k) are units for measuring volume. In (16h), a gallon of is a unit for measuring volume, equal to eight pints. In (16i), a litre of is a unit for measuring volume, especially liquids. In (16j), a pint of is a unit for measuring volume, equal to about half a litre. In (16k), a quart of is a unit for measuring liquid, equal to two pints. The partitives in (161-n) are units for measuring length. In (161), a metre of is a unit for measuring length, equal to 100 centimetres. In (16m), a mile of is a unit for measuring distance, equal to 1760 yards. In (16n), a yard of is a unit for measuring length, equal to three feet.

The following examples indicate how each partitive plays a different role within the facet of approximate measure.

(17) a. She threw a fistful of dirt in his face.

b. He pulled out $a$ handful of coins from his pocket. 
c. He only ate $a$ few mouthfuls of meat.

d. He added a spoonful of salt to the pasta water.

e. Add two cupfuls of milk to the mixture.

The examples under (17) contain partitives signifying approximate measure. In spite of that, each partitive represents a different facet, and so has a special task to perform in the language. In (17a), a fistful of is an amount of something that you can hold in your fist, especially cash, sand or money. In (17b), a handful of is an amount of something that can be held in one hand, especially money, stones or nuts. In (17c), a mouthful of is an amount of something that you put into your mouth at one time, especially food or drink. In (17d), a spoonful of is an amount that is held by a spoon, especially food. In (17e), a cupful of is an amount that a cup can hold, especially liquid.

\subsection{The Domain of QUALITY}

The domain of QUALITY is a knowledge structure referring to the peculiar and distinctive characteristic of someone or something. It refers to an intelligible feature by which a person or a thing may be identified. Quality has two facets: type and make. Type describes a group of things having some features that are the same. Linguistically, it is realised by such partitives as a breed of, a category of, a class of, a sort of, a species of, a strain of, a type of and a variety of. Make describes a product or the name of the manufacturer. Linguistically, it is realised by such partitives as $a$ brand of, a make of and a model of.

The following examples demonstrate how each partitive is assigned a different function within the facet of type.

(18) a. What's your favourite breed of dog?

b. There were different categories of voters.

c. Have you passed a test for this class of vehicle?

d. What sort of music do you like dancing to?

e. Over a hundred species of insect are found in this area.

f. Scientists have discovered a new strain of virus.

g. The floor was made of three different types of wood.

$\mathrm{h}$. The grocer on the corner sells different varieties of lettuce.

The examples listed in (18) contain partitives signalling type. Despite that, each partitive signifies a particular facet that earmarks its use in the language. In (18a), a breed of is a type of domestic animal such as dog, cat, horse, goat, sheep and cattle. In (18b), a category of is a type of people or things sharing appearance or quality. In (18c), a class of is a type of people or things having the same physical features or qualities. In (18d), a sort of is a type of things sharing similar qualities like music, shampoo, and so on. In (18e), a species of is a type of animals or plants having similar characteristics like fish, birds, tree, pandas, whales, and so on. In (18f), a strain of is a type of plant, virus or bacteria that has one particular feature that makes it different from others of the same type. In (18g), a type of is a group of people or things that are similar to each other in some way. In (18h), $a$ variety of is a type of plant that is different from another similar type like apple, lettuce, and so on.

Types of games are usually preceded by the partitive a game of. They include (i) board games such as billiards, chess, bridge, cards, darts, dominoes and table tennis, and (ii) field and court games such as football, volleyball, basketball, tennis, cricket, golf and badminton. Sample examples are How about a game of tennis this evening?, Let's have a game of chess today, Anybody fancy a game of golf this afternoon?

The following examples demonstrate how each partitive is assigned a different function within the facet of make.

(19) a. What brand of toothpaste do you use?

b. What make of car does she drive?

c. This model of Renault has five doors.

The examples listed in (19) contain partitives signalling make. Nevertheless, each partitive represents a different facet, and so has its own definition. In (19a), a brand of is a type of a product made by a particular company. It describes products such as food, drink or cleaning materials. In (19b), a make of is a type of a product identified by name as the product of a single firm or manufacturer. It describes products such as machines, equipment and cars. In (19c), a model of is a type of a product designed by a particular company. It describes designs of cars and household appliances. 
(20) a. Christine bought $a$ new pair of shoes.

b. He can't find a matching pair of socks.

c. He packed two new pairs of trousers.

The examples listed in (20) contain partitives naming products that come in pairs. Other products that follow the partitive a pair of are boots, braces, glasses, gloves, jeans, knickers, pants, pliers, pyjamas, scissors, shears, shorts, skates, skis, slippers, stockings, tights and tongs.

\subsection{The Domain of ABSTRACTION}

The domain of ABSTRACTION is a knowledge structure referring to things which do not exist as material objects. The things are non-count nouns which require partitives when items of them are to be presented. Abstraction consists of three facets. The first facet subsumes abstract nouns denoting proportions of knowledge: cognition and emotion. Linguistically, this facet is exemplified by such partitives as a piece of, a bit of, a grain of, a pang of, a glimmer of, a pearl of, a fraction of and a segment of. The second facet subsumes abstract nouns denoting areas of knowledge. Linguistically, this facet is exemplified by such partitives as an area of, a field of, a branch of, a realm of and a sphere of. The third facet subsumes abstract nouns denoting periods of time, usually short. Linguistically, this facet is exemplified by such partitives as a spell of, a stint of, a stretch of and $a$ term of.

The examples given below underline the distributions of the partitives within the facet of knowledge proportions.

(21) a. He did it without a bit of concern for human rights.

b. Let me give you a piece of advice on the matter.

d. There was not a grain of truth in what he said.

e. She felt a pang of guilt about leaving her friend.

c. The news gave a glimmer of hope for the future.

f. Thank you for those pearls of wisdom, Christine.

g. We paid only a fraction of the original price.

$\mathrm{h}$. The campaign targets a segment of the population.

The examples in (21) contain partitives which are used before nouns implying cognition and emotion. In spite of this, each partitive stands for a specific facet, and so has a special mission to carry out in the language. In (21a), a bit of is a very small amount of something like concern, fun or support. In (21b), a piece of is a small amount of something like advice, information or work. In (21c), a grain of is a very small amount of something like truth. In (21d), a pang of is a very small amount of feeling like guilt, pain or sadness. In (21e), a glimmer of is a small sign of something like hope or doubt. In (21f), a pearl of is a very small piece of knowledge. In (21g), $a$ fraction of is a very small amount of something like price or cost. In (21h), a segment of is a very small part of something like population or society.

The examples given below underline the distributions of the partitives within the facet of knowledge areas.

(22) a. The government called for reforms in the area of education.

b. There are employment opportunities in the field of healthcare.

c. Phonology is a branch of linguistics.

d. She is interested in the realm of practical politics.

e. She has a solid reputation in the sphere of science.

The examples in (22) contain partitives which are used before nouns denoting areas of knowledge, activity or interest. Despite that, each partitive manifests a different facet, and so plays a different role. In (22a), an area of refers to an area of knowledge, activity or responsibility like education, health or information technology. In (22b), a field of refers to an area of interest or study, especially one that you know a lot about like engineering, medicine or history. In (22c), a branch of refers to one part of a large area of knowledge or study like linguistics, mathematics or law. In (22d), a realm of refers to a general area of knowledge, activity or thought, like science fiction or practical politics. In (22e), a sphere of refers to an area of activity, interest or knowledge, which people respect or admire like diplomacy, politics or science.

The examples given below underline the distributions of the partitives within the facet of period of time. 
(23) a. He quit his job in a fit of depression.

b. They were lucky with a spell of dry weather for their picnic.

c. He has just finished $a$ stint of compulsory military service.

d. The elderly tend to sleep short stretches of time.

e. The Government's term of office expires at the end of the year.

The examples in (23) contain partitives which denote short periods. Yet, each partitive stands for a different facet, and so has its individual sense. In (23a), a fit of is a short, period of feeling that is sudden and uncontrolled such as temper or anger. In (23b), a spell of is a short period of activity that is of a particular kind such as weather or illness. In (23c), a stint of is a limited period of time doing a particular job or course such as military service or government service. In (23d), a stretch of is a continuous period of time, especially one during which there is not much activity such as sleeping. In (23e), a term of is a fixed period of time which something lasts for such as someone's period of responsibility or power, someone's period in prison, or a business contract.

In the preceding paragraphs, I showed how the domain theory applies to the description of partitives in English. The description comprises four steps. In the first step, I placed the partitives which share a concept under one domain. In the second step, I grouped the partitives within a domain into facets. In the third step, I identified the partitives which represent each facet within a domain. In the fourth step, I pinpointed the peculiarity of each partitive which makes it different from its counterpart in the domain. When and how to use a partitive is a matter decided by the speaker. The choice of the speaker comes under the rubric of construal. Construal is concerned with the way the speaker conceives a situation and the choice of the right expression to realise it. Two, or more, partitives which stand as rivals construe a situation in different ways. Each partitive represents a different conceptualisation of experience. The elaboration of this cognitive tenet will be the task of the following section.

\section{The Construal Theory}

Cognitive Grammar describes seemingly similar pairs according to the construal theory, as exemplified by Langacker (1987, 1991a). In view of this theory, the meaning of a concept is described relative to the way a scene is construed. Construal is the ability of the speaker to conceptualise a situation differently. In language, the meaning of a lexical item includes two aspects: conceptual content and construal. Conceptual content is the semantic property inherent in a situation. Construal is the ability of the speaker to conceptualise a situation differently and use different linguistic expressions to represent these different conceptualisations in discourse. Two lexical items may share the same content, but they embody alternative construals of the content. In each alternative, the speaker adjusts his/her conceptualisation and focuses on a particular aspect of the situation s/he describes. That is why each alternative is realised in language differently.

The difference resides in the alternate ways the situation is described, which is a matter of the construal imposed on its content. One dimension of construal that is at work here is called perspective. According to Langacker (1988, p. 84), perspective is the viewpoint which the speaker imposes on a scene. The viewpoint changes according to the communicative demand. Two expressions sharing content differ in meaning due to the different viewpoints of the speaker. Each expression designates a particular perspective of the speaker. Consequently, the perspective embodied by a linguistic expression constitutes a crucial facet of its meaning. For example, the items defender and defendant refer to someone who defends, but each item is construed differently. The difference relates to the perspective taken by the speaker. The speaker uses defender when s/he construes someone as defending a person, idea or plan. The speaker uses defendant when $\mathrm{s} / \mathrm{he}$ construes someone as defending himself/herself in a court of law.

The construal theory is applicable to almost every area of language (Note 2). In the present analysis, I extend its impact to the description of partitives. In this connection, I argue that the choice of a partitive correlates with the particular construal imposed on a scene. At first sight, a pair of partitives may appear to be synonymous. A closer look, however, reveals that they are neither identical in meaning nor interchangeable in use. There is a clear-cut distinction in their use. There are two keys to using them correctly. One key is to know that a pair of partitives constitutes different conceptualisations of the same situation. The different conceptualisations reflect different perspectives of the speaker. The other key is to know that, as a result, the two expressions are realised linguistically differently. In each case, it is the form of the partitive that encodes the intended conceptualisation. The different partitives, therefore, single out different aspects of the meaning of the expression.

Some examples will make this clear. The speaker has the ability to conceptualise a situation in two ways: either as substance or as individuals. Depending on the speaker's perspective, the same entity can be used to express either unbounded or bounded concepts. Each use represents a different viewpoint of the speaker. A mass noun is 
treated as a continuous entity, having no natural bounds. A count noun is treated as a separable entity, having natural bounds. The process of converting an unbounded mass entity into a bounded count entity signalling a portion of the mass is called excerpting. Excerpting contrasts with a grammatical process known as debounding, the process of converting a count entity into a mass entity. In the examples He needs wood to make a sculpture, and He needs a block of wood to make a sculpture the word wood represents a mass-count distinction. In the first, wood is a mass noun. It is unbounded. It is conceived as substance. In the second, wood is a count noun. It is bounded. It is conceived as individual. In the examples, the mass noun wood undergoes an excerpting operation by virtue of the partitive $a$ block of which serves to excerpt a portion of the unbounded entity wood.

Within individuation, the act of extracting discrete individual units, there are different ways to conceptualise a situation. Phrased differently, the same situation can be construed differently, and so each time a different lexical item is used. An example will clarify this. The partitives a sip of, a glass of and a drink of collocate with a noun denoting liquids like wine. Yet, each partitive construes the content of the situation in a different fashion. A sip of is a very small amount of a drink, as in He tried a sip of wine to see if he liked it. It is a small draft taken with the lips. A glass of is an amount of liquid contained in a glass, as in She poured herself a glass of wine. It is the quantity held by a glass container. A drink of is an amount of liquid that one drinks, as in He asked for a drink of wine. It is a portion of liquid. This shows that construal does not only depend on how things really are, but also on how they are conceptualised.

In what follows, I introduce the different perspectives taken on the situations, which represent different construals. The goal is to show that partitives represent different construals and so carry out different functions in the language. Partitives occurring in the same position exhibit semantic distinctions. This helps to avoid the fallacy that similar-looking pairs are synonymous, as pre-cognitive accounts mistakenly assume. The introduction comprises five steps. First, a list of parititives occurring before the same nouns is compiled. Second, the semantic distinctions reflecting different construals are pinpointed. Third, pairs of parititives representing the distinctions are identified. Fourth, pairs of sentences demonstrating the uses of the alternative pairs of partitives are provided. To make the sentences user-friendly, some are made more concise. Fifth, the pairs are distinguished by analysing their contextual preferences.

\subsection{The Small-Large Distinction}

(24) a. There is a speck of dust in the air.

b. There is a cloud of dust in the air.

In the two examples in (24), the noun dust is preceded by two different partitives denoting size: a speck of in (24a) and a cloud of in (24b). Yet, each partitive represents a particular construal and so causes a nuance of meaning. In (24a), the partitive a speck of means "a very small amount of something that is difficult to see". A speck of dust is a small spot of dust. In (24b), the partitive a cloud of means "a large amount of something that looks like a cloud". A cloud of dust is a mass of dust.

\subsection{The Light-Heavy Distinction}

(25) a. They need a pint of milk.

b. They need a quart of milk.

In the two examples in (25), the noun milk is preceded by two different partitives denoting measure: a pint of in (25a) and a quart of in (25b). Nevertheless, construal connects them to different uses. In (25a), a pint of means "a unit of measurement for liquids". A pint of milk is an amount of milk equal to about half a litre. In (25b), $a$ quart of means "a unit of measurement for liquids". A quart of milk is an amount of milk equal to two pints.

\subsection{The Flat-Square Distinction}

(26) a. A sheet of ice floated on the lake.

b. A block of ice floated on the lake.

In the two examples in (26), the noun ice is preceded by two different partitives denoting shape: a sheet of in (26a) and $a$ block of in (26b). Nonetheless, a difference in construal keeps the two partitives apart. In (26a), the partitive $a$ sheet of means "a large piece of thin flat material". A sheet of ice is a large thin flat rectangular piece of ice. In (26b), the partitive a block of means "a large piece of thick square material". A block of ice is a large thick square piece of ice. 


\subsection{The Part-Whole Distinction}

(27) a. She wants $a$ slice of bread.

b. She wants a loaf of bread.

In the two examples in (27), the noun bread is preceded by two different partitives denoting amount: $a$ slice of in (27a) and a loaf of in (27b). Even so, construal separates the two partitives from each other. In (27a), the partitive a slice of is "a portion of something cut from a larger piece". A slice of bread is a part of bread that has been cut from a whole. In (27b), the partitive a loaf of is "all of something that is baked in one piece". A loaf of bread is the whole of bread that is baked in a single piece.

\subsection{The Small-Large Container Distinction}

(28) a. He bought a packet of cigarettes.

b. He bought $a$ carton of cigarettes.

In the two examples in (28), the noun cigarette is preceded by two different partitives denoting container: $a$ packet of in (28a) and a carton of in (28b). However, each partitive signifies a different construal of the scene, and so has a distinct use. In (28a), the partitive a packet of is "a small paper or cardboard container in which a number of small objects are sold". A packet of cigarettes is a small container which holds 20 cigarettes. In (28b), a carton of is "a large cardboard container in which small objects are sold". A carton of cigarettes is a large container which holds 20 packets of cigarettes.

\subsection{The Moving-Stagnant Distinction}

(29) a. A throng of fans had gathered round the stage.

b. A crush of fans had gathered round the stage.

In the two examples in (29), the noun fan is preceded by two different partitives denoting an assembled multitude usually of people: a throng of in (29a) and a crush of in (29b). However, they display a difference in use, which is related to construal. In (29a), the partitive a throng of is "a large group pf people". A throng of fans is a crowd of fans characterised by movement and pushing. In (29b), the partitive $a$ crush of is "a large group of people". A crush of fans is a crowd of fans characterised by difficulty of individual movement and the attendant discomfort.

\subsection{The Content-Container Distinction}

(30) a. He needs two pints of liquid.

b. He needs two bottles of liquid.

In the two examples in (30), the noun liquid is preceded by two different partitives: a pint of in (30a) and a bottle of in (30b). Nevertheless, each partitive symbolises a certain construal and so has its individual sense. In (30a), the partitive $a$ pint of is "a unit for measuring liquids". A pint of liquid is a measure for liquid, equal to about half a litre. In (30b), the partitive a bottle of is "a container with a narrow neck, usually made of glass or plastic, for keeping liquids in". A bottle of liquid is a container for holding liquids.

\subsection{The Single-Group Distinction}

(31) a. She tucked $a$ strand of hair behind her ears.

b. She tucked $a$ lock of hair behind her ears.

In the two examples in (31), the noun hair is preceded by two different partitives: a strand of in (31a) and a lock of in (31b). Still, the noun is construed differently and so each partitive has its own sense. In (31a), the partitive $a$ strand of means "a single thin piece of something". A strand of hair is a thin thread of hair. In (31b), the partitive a lock of means "a small group of something". A lock of hair is a small group of hairs, especially a curl.

\subsection{The Type-Genus Distinction}

(32) a. Spaniels are my favourite breed of dog.

b. Spaniels are my favourite species of $\mathrm{dog}$.

In the two examples in (32), the noun $d o g$ is preceded by two different partitives: a breed of in (32a) and $a$ species of in (32b). Still, each partitive construes the noun differently and so adds a special meaning to it. In (32a), the partitive a breed of means "a type of domestic animal". A breed of dog is a particular type of dog. In (32b), the partitive a species of means "a group of animals that are all similar and can breed together to produce young animals of the same type". A species of dog is a set of dogs in which the members have similar 
characteristics to each other.

\subsection{The Essential-Superficial Distinction}

(33) a. This is a kind of fruit.

b. This is a sort of fruit.

In the two examples in (33), the noun fruit is preceded by two different partitives denoting a number of individuals thought of as a group because of a common quality or qualities: a kind of in (33a) and $a$ sort of in (33b). In spite of this, construal draws a line of separation between them. In (33a), the partitive $a$ kind of means "a type of a thing that belongs to the same group". A kind of fruit is fruit that displays essential resemblance to the group. In (33b), the partitive a sort of means "a type of a thing that belongs to the same group". A sort of fruit is fruit that displays superficial resemblance to the group (Note 3).

\section{Conclusion}

This paper has shed light on partitives in English. A partitive is a word used to describe only part of a noun. In the literature, partitives have neither been explained in detail nor covered in a systematic manner. To remedy the situation, I have adopted Cognitive Grammar and substantiated some of its fundamental tenets to the analysis of partitives. Based on these tenets, I have found four patterns in which partitives occur. First, some partitives have a narrow range of collocation, and so are associated with only one noun. The partitive a clove of, for example, occurs only with garlic. A clove of means a small separate part of a garlic plant. Second, some partitives have a wide range of collocation, and so are associated with more than one noun, as in a sack of ricelflour, a bucket of sand/water, a tub of ice cream/popcorn, etc. This is due to the semantic make-up of the partitive. Third, some partitives gather in domains, in which each partitive designates a particular facet of experience, as in a horde of/a throng of/a crush of/a gang of/a panel of, which evoke the domain of a crowd of people, but of different nature. Fourth, some pairs of partitives occur before same nouns, but they are not synonymous. The distinction resides in the alternate ways the situation is construed, which is realised by different partitives. In each alternative, the partitive shifts the meaning of the expression to a certain direction, and so encodes a different construal. In $a$ bit/piece of wood, for example, the partitive $a$ bit of suggests a smaller amount than the partitive a piece of. There is thus a correlation between differences in construal and structure. The patterns in which partitives occur show how Cognitive Grammar brings more descriptive and explanatory adequacy on linguistic analysis.

\section{References}

Alexander, L. G. (1988). Longman English Grammar. London: Longman.

Biber, D., Johansson, S., Leech, G., Conrad, S., \& Finegan, E. (1999). Longman Grammar of Spoken and Written English. Harlow: Longman.

Cambridge Advanced Learner's Dictionary. (2003). Cambridge: Cambridge University Press.

Hamawand, Z. (2002). Atemporal Complement Clauses in English: A Cognitive Grammar Analysis. München: Lincom.

Hamawand, Z. (2003). For-to complement clauses in English: A Cognitive Grammar Analysis. Studia Linguistica, 57, 171-192. http://dx.doi.org/10.1111/j.0039-3193.2003.00103.x

Hamawand, Z. (2007). Suffixal Rivalry in Adjective Formation. A Cognitive-Corpus Analysis. London: Equinox.

Hamawand, Z. (2008). Morpho-Lexical Alternation in Noun Formation. London: Palgrave Macmillan. http://dx.doi.org/10.1057/9780230584013

Hamawand, Z. (2009). The Semantics of English Negative Prefixes. London: Equinox.

Hamawand, Z. (2011). Morphology in English: Word formation in Cognitive Grammar. London: Continuum.

Hoeksema, J. (Ed.). (1996). Studies on the syntax and semantics of partitive and related constructions. Berlin: Mouton de Gruyter. http://dx.doi.org/10.1515/9783110908985

Huddleston, R., \& Pullum, G. (2002). The Cambridge grammar of the English Language. Cambridge: Cambridge University Press.

Huddleston, R., \& Pullum, G. (2005). A Student's Introduction to English Grammar. Cambridge: Cambridge University Press. http://dx.doi.org/10.1017/CBO9780511815515

Jackendoff, R. (1991). Parts and Boundaries. In Levin, \& Pinker (Eds.), Lexical and Conceptual Semantics. Amsterdam: Elsevier Science Publishers. 
Koptjevskaja-Tamm, M. (2006). Partitives. In K. Brown (Ed.), Encyclopedia of Languages and Linguistics (pp. 218-221). Oxford: Elsevier.

Langacker, R. (1987). Foundations of Cognitive Grammar: Vol. 1. Theoretical Prerequisites. Stanford: Stanford University Press.

Langacker, R. (1988). A view of linguistic semantics. In B. Rudzka-Ostyn (Ed.), Topics in Cognitive Linguistics (pp. 49-90).

Langacker, R. (1991a). Foundations of Cognitive Grammar: Vol. 2. Descriptive Application. Stanford: Stanford University Press.

Langacker, R. (1991b). Concept, Image and Symbol. Berlin: Mouton de Gruyter. http://dx.doi.org/10.1515/9783110857733

Langacker, R. (1997). The contextual basis of cognitive semantics. In J. Nuyts, \& E. Pederson (Eds.), Language and Conceptualisation (pp. 229-232). http://dx.doi.org/10.1017/CBO9781139086677.010

Langacker, R. (1999). Grammar and Conceptualisation. Berlin: Mouton de Gruyter. http://dx.doi.org/10.1515/9783110800524

Langacker, R. (2008). Cognitive Grammar: A Basic Introduction. Oxford: Oxford University Press. http://dx.doi.org/10.1093/acprof:oso/9780195331967.001.0001

Longman Dictionary of Contemporary English. (2009). Harlow: Pearson.

Longman Language Activator. (2002). Essex: Longman.

Lyons, J. (1977). Semantics. Cambridge: Cambridge University Press. http://dx.doi.org/10.1017/CBO9780511620614

Oxford Advanced Learner's Dictionary of Current English. (2005). Oxford: Oxford University Press.

Quirk, R., Greenbaum, S., Leech, G., \& Svartvik, J. (1985). A Comprehensive Grammar of the English Language. London: Longman.

The New Merriam-Webster Dictionary. (1989). Mass.: Springfield.

\section{Notes}

Note 1. In Hamawand (2003), I applied the cognitive domain theory to the description of verbs taking for-to complement clauses in English. In Hamawand (2007, 2008), I applied it to the description of suffixes. In Hamawand (2009), I applied it to the description of negative prefixes.

Note 2. In Hamawand (2002), I applied the construal theory to the description of complement clauses in English. In Hamawand $(2007,2008)$, I applied it to the description of suffixes. In Hamawand (2009), I applied it to the description of negative prefixes.

Note 3. Other examples are a cube/lump of sugar, a bowl/pot of soup, a bag/basket of shopping, a pile/heap of toys, a case/crate of beer, and so on.

\section{Copyrights}

Copyright for this article is retained by the author(s), with first publication rights granted to the journal.

This is an open-access article distributed under the terms and conditions of the Creative Commons Attribution license (http://creativecommons.org/licenses/by/3.0/). 